\title{
Single center experience in laparoscopic treatment of gallbladder perforation
}

\author{
Nuri Alper Sahbaz ${ }^{1}$, Kivanc Derya Peker ${ }^{1}$, Hamit Ahmet Kabuli ${ }^{1}$, Alpen Yahya Gumusoglu ${ }^{1}$, Halil Alis ${ }^{2}$ \\ ${ }^{1}$ Bakirkoy Dr. Sadi Konuk Training and Research Hospital, Istanbul, Turkey \\ ${ }^{2}$ Department of General Surgery, Faculty of Medicine, Istanbul Aydın University, Istanbul, Turkey
}

Videosurgery Miniinv 2017; 12 (4): 372-377

DOI: https://doi.org/10.5114/wiitm.2017.72321

\begin{abstract}
Introduction: Gallbladder perforation (GBP) is a rare disease with potential mortality. Previous series have reported an incidence of approximately $2-11 \%$ and it still continues to be a significant problem for surgeons.

Aim: To present our clinical experience with gallbladder perforation.

Material and methods: The records of 2754 patients who received surgical treatment for cholelithiasis between 2010 and 2016 were reviewed retrospectively. One hundred thirty-three patients had gallbladder perforation. Age, gender, time from the onset of symptoms, diagnostic procedures, surgical treatment, morbidity and mortality rates were evaluated.

Results: $15.78 \%$ of patients had a body mass index $>35.6 .76 \%$ had chronic obstructive pulmonary disease, $6.76 \%$ had cardiac disease, $10.52 \%$ had diabetes and $4.51 \%$ had sepsis. American Society of Anesthesiology scores were I in $54.13 \%$, II in $35.33 \%$, III in $6.01 \%$ and IV in $4.51 \%$ of the patients. $27.81 \%$ of patients were diagnosed during surgery. The perforation site was the gallbladder fundus in $69.17 \%$, body in $17.30 \%$, Hartman's pouch in $10.53 \%$ and cystic duct in $3 \%$ of patients. Treatment modalities were laparoscopic cholecystectomy in $82.71 \%$, open cholecystectomy in $3 \%$, percutaneous drainage catheters + laparoscopic cholecystectomy in 3\%, laparoscopic cholecystectomy + fistula repair in $10.53 \%$ and open cholecystectomy + fistula repair in $0.75 \%$ of patients. Mean length of hospital stay was 1.69 days. Mortality and morbidity rates were $8.27 \%$ and $10.52 \%$, respectively. Histopathology results were acute cholecystitis in 69.93\%, chronic cholecystitis in 20.30\% and acute exacerbation over chronic cholecystitis in $9.77 \%$ of patients.

Conclusions: Appropriate classification and management of perforated cholecystitis is essential. Laparoscopic cholecystectomy is a safe and feasible method to decrease morbidity in gallbladder perforations.
\end{abstract}

Key words: acute cholecystitis, gallbladder perforation, cholecystectomy, fistula.

\section{Introduction}

Gallbladder perforation (GBP) is a rare disease with potential mortality. Previous series have reported an incidence of approximately 2-11\% [1-4]. Gallbladder perforation still continues to be a significant problem for surgeons. It is associated with morbidity and mortality, and unfortunately its early detection may be difficult and most cases can only be diagnosed at the time of surgery $[5,6]$.

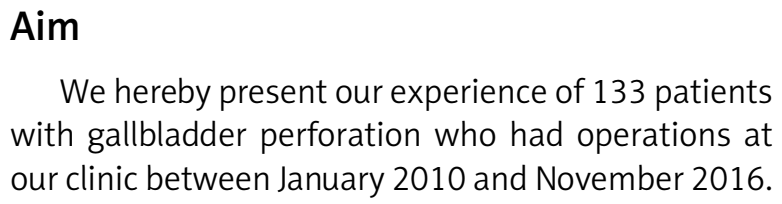

We hereby present our experience of 133 patients with gallbladder perforation who had operations at our clinic between January 2010 and November 2016. 


\section{Material and methods}

The present retrospective study was conducted at Bakirkoy Dr. Sadi Konuk Training and Research Hospital, Istanbul, Turkey. The records of 2754 patients who received surgical treatment for cholelithiasis at our institution between January 2010 and November 2016 were evaluated retrospectively. Only patients with GBP were considered for this study. Perforations due to trauma, iatrogenic causes, and gallbladder (GB) carcinoma were excluded. One hundred thirty-three consecutive cases of gallbladder perforation were included in our study.

The patients were classified according to Niemeier's classification of gallbladder perforation (type I: acute free perforation into the peritoneal cavity, type II: subacute perforation with pericholecystic abscess, and type III: chronic perforation with cholecysto-enteric fistula) [2].

Demographic features, comorbidities, mode of diagnosis, type of surgery, outcome measures, intraand postoperative complications, which were classified according to the Clavien-Dindo classification, mortality rates, length of hospital stay, site of perforation, and histopathology results were analyzed. American Society of Anesthesiology (ASA) scores were calculated by anesthesiologists.

The patients underwent surgery after administration of intravenous crystalloid solutions, and were treated with analgesics and antibiotics ( $3^{\text {rd }}$ genera- tion cephalosporins) within the first $36 \mathrm{~h}$ (mean: $9 \mathrm{~h}$ ) after admission. Patients with co-morbidities such as diabetes, chronic obstructive pulmonary disease (COPD), and ischemic heart disease (IHD) underwent surgery after specific medical treatment was started. The antibiotic regimen was changed when required, according to the results of microbiological assessment of the infected bile specimens obtained from the gall bladder.

Postoperative bile leak was defined as ongoing bilious drainage of any amount through the drainage tube or the percutaneous drainage catheter lasting for more than 3 weeks.

Morbidity was defined as an unexpected event within 90 days after surgical intervention or during the same hospital admission, which was harmful for the patient's health and required a change of therapeutic strategy. Mortality was defined as any death within 90 days after surgical intervention or during the same hospital admission.

\section{Results}

One hundred and thirty-three patients were included in this study. Mean age was 64.33 (55-77) years and the female-to-male ratio was $1 / 2$. Demographic data and their distributions among the types of perforation are shown in Table I.

As co-morbidity, $15.78 \%$ of patients had a body mass index (BMI) $>35 \mathrm{~kg} / \mathrm{m}^{2}, 6.76 \%$ had COPD, 6.76\% had

Table I. Demographic features

\begin{tabular}{|lcccc|}
\hline Parameter & Total & Type I & Type II & Type III \\
\hline Number of cases & 133 & $66(49.62 \%)$ & $52(39.1 \%)$ & $15(11.28 \%)$ \\
\hline Mean age [years] & 64.33 & 62.5 & 64.5 & 71.8 \\
\hline Sex (F/M) & $1 / 2$ & $16 / 50$ & $22 / 30$ & $5 / 10$ \\
\hline
\end{tabular}

Table II. Co-morbidities

\begin{tabular}{|lcccc|}
\hline Parameter & Percentage & Type I $(n)$ & Type II $(n)$ & Type III $(n)$ \\
\hline BMI $>35 \mathrm{~kg} / \mathrm{m}^{2}$ & 15.78 & 11 & 7 & 3 \\
\hline COPD & 6.76 & 4 & 3 & 2 \\
\hline Cardiac history & 6.76 & 5 & 2 & 2 \\
\hline Diabetes & 10.52 & 6 & 5 & 3 \\
\hline Sepsis & 4.51 & 3 & 2 & 7 \\
\hline Total & 40.6 & 26 & 21 & 7 \\
\hline
\end{tabular}


a history of cardiac disease, $10.52 \%$ had diabetes and $4.51 \%$ had sepsis. Co-morbidities and their distributions among the types of perforation are shown in Table II.

American Society of Anesthesiology scores were I in $54.14 \%$, II in $35.33 \%$, III in $6.02 \%$ and IV in $4.51 \%$ of patients. ASA scores and their distributions among the types of perforation are shown in Table III.

Preoperative modes of diagnosis were ultrasound (US) scan in $42.10 \%$, abdominal computed tomography (CT) scan in $28.57 \%$ and magnetic resonance cholangiopancreatography (MRCP) in 1.5\% of patients. $27.81 \%$ of patients were diagnosed at the time of surgery. Preoperative modes of diagnosis and their distributions among the types of perforation are shown in Table IV.

The perforation site was the gallbladder fundus in $69.71 \%$, body in $17.30 \%$, Hartman's pouch in $10.53 \%$ and cystic duct in 3\% of patients. Perforation sites and their distributions among the types of perforation are shown in Table $\mathrm{V}$.

Treatment modalities were laparoscopic cholecystectomy (LC) in $82.71 \%$, open cholecystectomy
(OC) in 3\%, percutaneous drainage catheters (PDC) + LC in 3\%, LC + fistula repair in $10.53 \%$ and OC + fistula repair in $0.75 \%$ of patients. Mean length of hospital stay was 1.69 days. Treatment modalities and mean length of hospital stay and their distribution among the types of perforation are shown in Table VI.

Mortality and morbidity rates were $8.27 \%$ and $10.52 \%$ respectively. Mortality rates, complications according to the Clavien-Dindo classification, their clinical outcomes and distribution among the types of perforation are shown in Table VII.

Postoperative histopathology results were acute cholecystitis in $69.17 \%$, chronic cholecystitis in $19.54 \%$ and acute exacerbation over chronic cholecystitis in $9.02 \%$ of patients. Their distributions among the types of perforation are shown in Table VIII.

\section{Discussion}

The incidence of gallbladder perforation in our series is $4.8 \%$, which is in accordance with the cur-

Table III. ASA scores

\begin{tabular}{|lcccc|}
\hline ASA score & Percentage & Type I $(n)$ & Type II $(n)$ & Type III $(n)$ \\
\hline I & 54.14 & 35 & 31 & 6 \\
\hline II & 35.33 & 24 & 18 & 5 \\
\hline III & 6.02 & 6 & 0 & 2 \\
\hline IV & 4.51 & 1 & 3 & 2 \\
\hline
\end{tabular}

Table IV. Preoperative modes of diagnosis

\begin{tabular}{|lcccc|}
\hline Methods & Percentage & Type I $(n)$ & Type II $(n)$ & Type III $(n)$ \\
\hline Abdominal US & 42.11 & 36 & 18 & 2 \\
\hline Abdominal CT scan & 28.57 & 21 & 10 & 7 \\
\hline MRCP & 1.50 & 0 & 0 & 2 \\
\hline At the time of surgery & 27.82 & 9 & 24 & 4 \\
\hline
\end{tabular}

Table V. Site of perforation

\begin{tabular}{|lcccc|}
\hline Perforation & Percentage & Type I $(n)$ & Type II $(n)$ & Type III $(n)$ \\
\hline Fundus & 69.17 & 50 & 35 & 9 \\
\hline Body & 17.30 & 9 & 6 & 5 \\
\hline Hartman's pouch & 10.53 & 6 & 2 & 2 \\
\hline Cystic duct & 3 & 1 & 9 \\
\hline
\end{tabular}


Table VI. Surgery performed and mean length of hospital stay

\begin{tabular}{|lcccc|}
\hline Variable & Percentage & Type I $(n)$ & Type II $(n)$ & Type III $(n)$ \\
\hline LC & 82.71 & 62 & 48 & 0 \\
\hline OC & 3 & 3 & 1 & 0 \\
\hline PCD + LC & 3 & 1 & 3 & 0 \\
\hline LC + fistula repair & 10.53 & 0 & 0 & 14 \\
\hline OC + fistula repair & 0.75 & 0 & 1.5 & 4.1 \\
\hline Mean length of hospital stay [day] & 1.69 & 1.3 & 0 & 1 \\
\hline
\end{tabular}

Table VII. Morbidity and mortality

\begin{tabular}{|lcccc|}
\hline Morbidity & Percentage & Type I $(n)$ & Type II $(n)$ & Type III $(n)$ \\
\hline $\begin{array}{l}\text { Clavien-Dindo class 1 } \\
\text { (electrolytes imbalance } \\
\text { and postoperative paralytic ileus) }\end{array}$ & 4.51 & 4 & 1 & 1 \\
\hline $\begin{array}{l}\text { Clavien-Dindo class 2 } \\
\text { (wound infection) }\end{array}$ & 5.26 & 5 & 2 & 0 \\
\hline $\begin{array}{l}\text { Clavien-Dindo class 3 } \\
\text { (post-operative persistent bile leak) }\end{array}$ & 0.75 & 0 & 0 & 0 \\
\hline Clavien-Dindo class 4 & 0 & 0 & 0 & $2(13.33 \%)$ \\
\hline Total & 10.52 & $9(13.63 \%)$ & $3(5.76 \%)$ & 0 \\
\hline Mortality & 8.27 & 7 & 4 & 0 \\
\hline
\end{tabular}

Table VIII. Postoperative histopathology results

\begin{tabular}{|lcccc|}
\hline Variable & Percentage & Type I $(n)$ & Type II $(n)$ & Type III $(n)$ \\
\hline Acute cholecystitis & 69.93 & 56 & 34 & 3 \\
\hline Chronic cholecystitis & 20.30 & 0 & 16 & 11 \\
\hline $\begin{array}{l}\text { Acute exacerbation over chronic } \\
\text { cholecystitis }\end{array}$ & 9.77 & 8 & 3 & 2 \\
\hline
\end{tabular}

rent literature that reports an incidence of $2 \%$ to $10 \%$ [1-4]. When the demographic data are analyzed, all 3 types of perforations are seen more frequently in men, also supporting the literature $[7,8]$. Gallbladder perforation is usually seen over the age of 60 . Stefanidis et al. reported that types I and II GBP tend to occur in younger patients [7]. In our series it is seen over the age of 60; in fact, mean age of type 3 was 71.8. According to the literature GBP type I is seen in $68 \%$, type II in $16 \%$ and type III in $16 \%$ of patients. In our series the distribution of GBP types is as follows: type $\mathrm{I}=49.6 \%$, type $\mathrm{II}=39.1 \%$ and type III $=11.3 \%$. It can be generally assumed that it is seen in men over 60 .
In our series $40.6 \%$ of patients had co-morbidities. Most of the patients were morbidly obese and had atherosclerotic heart disease and diabetes. Infections, malignancy, trauma, drugs (e.g. corticosteroids) and systemic diseases are the predisposing factors. Especially diabetes mellitus (DM) and atherosclerotic heart disease are defined as risk factors and are observed in 50\% of patients [7].

Fundus, the most distal part with regard to the blood supply, is the site of perforation in $60 \%$ of cases [3]. In our series, fundus perforation was seen in $69 \%$. High rates of fundus and type I perforations may explain the high diagnostic values of US and CT scans, which gives the surgeon the opportunity to 
make a pre-operative diagnosis instead of an unexpected surprise at the time of surgery. When type I perforations were seen with fundus perforations, these patients usually presented with acute abdomen, instead of a silent perforation following chronic cholecystitis and fistula formation as seen in type III perforations. In these patients standard abdominal CT plays an important role in diagnosing gallbladder perforation. Upper abdominal CT for acute cholecystitis, in which pericholecystic fluid was found by ultrasonography, may increase the rate of preoperative diagnosis of gallbladder perforation [8]. The advantage of MRCP is its superb ability to detect stones in the bile ducts, biliary dilatation and the relationship of a pericholecystic fluid collection to the abdominal wall and gallbladder. This information can aid in surgical planning [9]. However, MRCP use is usually limited to fistula evaluation.

Laparoscopic cholecystectomy can be performed for acute, gangrenous, and/or perforated cholecystitis. Being feasible and safe, laparoscopic cholecystectomy is also cheaper than open procedures [10], but conversion may be necessary in case of difficulty such as an obscure anatomy [8]. Especially, as type II perforations are frequently related to subacute cholecystitis, they can be mistaken for frozen Calot's triangle. Most surgeons hesitate to operate on subacute cholecystitis and tend to postpone the surgery [11]. Nevertheless, our institution's approach to subacute cholecystitis is surgery at the time of diagnosis, and we have favorable outcomes. In a study by Ausania et al. laparoscopic surgery was found to decrease mortality in perforated gallbladder [5]. This decrease is attributed to the reduced complication rates of laparoscopic surgery.

Gallbladder perforation in acalculous cholecystitis is a rare condition and it has a mortality rate of $10-30 \%$ [12-14]. Glenn et al. [15] reported the mortality rate as being $42 \%$ in gallbladder perforation patients, while other studies have reported that the mortality rates have decreased to $12-16 \%$ owing to the developments in anesthesiology and intensive care conditions [16-18]. Preoperative sepsis was certainly a determinant factor associated with mortality and morbidity. Its role as a risk factor for postoperative complications and death has already been described in abdominal surgery, including hepatobiliary surgery [18-20]. Our mortality rate was $8.27 \%$, and in all of these cases there was uncontrolled sepsis. ASA scores were found to have no impact on mortality because all of our mortality cases were ASA II and ASA III. Our small numbers of ASA IV patients might be one of the reasons, but when our general approach is evaluated, the use of percutaneous drainage and transfer of patients to the intensive care unit (ICU) for stabilization before the definitive surgery might have also decreased our mortality rates for ASA IV patients. Furthermore, the ASA score has less value than the acute physiology and chronic health evaluation II (APACHE-II) score in predicting mortality in perforated cholecystitis. However, in general, ASA scores, APACHE-II scores and the physiological and operative severity score for the enumeration of mortality and morbidity (POSSUM) were insufficient in predicting mortality [5].

Several authors have reported morbidity rates of GBP about 50\% [5]. Our morbidity rate was $10.52 \%$. Complications in the literature are usually reported as surgical site infections and not classified according to Clavien-Dindo or any other classification. In our series, especially in type I perforations, most of the complications were surgical site infections, electrolyte imbalance and postoperative paralytic ileus. In one patient, who had a type III perforation, a persistent leak was observed from the duodenal repair site. Our low morbidity rates can be explained by a decrease in surgical site infections as a result of the laparoscopic approach. There was no significant difference in length of hospital stay between type I and type II perforations. Length of hospital stay was 4.1 days in type III perforations and all patients but one had a laparoscopic fistula repair in this group. However, fistula repair obviously increased hospital stay. The vast experience with laparoscopic surgery nowadays has made laparoscopic cholecystectomy the current gold standard, with exceptionally good results even in very complex cases [21]. In our series, length of hospital stay is shorter than that in the general literature (9.5 days), because of our persistence in the laparoscopic approach [5-8]. Another possible reason for this decrease in the length of hospital stay could be the availability of home care for the patients and follow-up of the surgical site infections and non-persistent leaks on an outpatient basis.

When our histopathology results were evaluated, the results were in accordance with Neimeier's classification. While type I perforations were usually related to acute cholecystitis, type III perforations were found to be associated with chronic cholecystitis [3]. 


\section{Conclusions}

With the large number of cases in our series, we can state that all types of GBP can be safely treated by the laparoscopic approach. Except for the ASA IV patients, all patients can be treated with surgery, without making a distinction between acute, subacute or chronic cholecystitis.

\section{Conflict of interest}

The authors declare no conflict of interest.

\section{References}

1. Bedirli A, Sakrak O, Sözüer EM, et al. Factors effecting the complications in the natural history of acute cholecystitis. Hepatogastroenterology 2001; 48: 1275-8.

2. Niemeier OW. Acute free perforation of the gall-bladder. Ann Surg 1934; 99: 922-4

3. Abu-Dalu J, Urca I. Acute cholecystitis with perforation into the peritoneal cavity. Arch Surg 1971; 102: 108-10.

4. Menakuru SR, Kaman L, Behera A, et al. Current management of gall bladder perforations. ANZ J Surg 2004; 74: 843-6.

5. Ausania F, Guzman Suarez S, Alvarez Garcia H, et al. Gallbladder perforation: morbidity, mortality and preoperative risk prediction. Surg Endosc 2015; 29: 955-60.

6. Ong CL, Wong TH, Rauff A. Acute gall bladder perforation: a dilemma in early diagnosis. Gut 1991; 32: 956-8.

7. Stefanidis D, Sirinek KR. Gallbladder perforation: risk factors and outcome. J Surg Res 2006; 131: 204-8.

8. Derici H, Kara C, Bozdag AD, et al. Diagnosis and treatment of gallbladder perforation. World I Gastroenterol 2006; 12 : 7832-6.

9. Karcaaltincaba M, Hohenwalter MD, Erickson SJ, Taylor AJ. MRCP findings of gallbladder perforation and pericholecystic abscess. CMIG Extra Cases 2004; 28: 59-61.

10. Śmigielski JA, Piskorz L, Koptas W. Comparison of treatment costs of laparoscopic and open surgery. Videosurgery Miniinv 2015; 10: 437-41

11. Akarsu C, Dural AC, Kones O, et al. Emergency cholecystectomy versus percutaneous cholecystostomy for treatment of acute cholecystitis in high-risk surgical patients. Int Surg 2016 https://doi.org/10.9738/INTSURG-D-16-00076.1.

12. Morris BS, Balpande PR, Morani AC. CT appearance of gallbladder perforation. Br J Radiol 2007; 80: 898-901.

13. Wig JD, Chowdhary A, Talwar BL. Gall bladder perforations. Aust N Z J Surg 1984; 54: 531-4.

14. Smith EB. Perforation of the gallbladder: a clinical study. J Natl Med Assoc 1981; 73: 333-5.

15. Glenn F, Moore SW. Gangrene and perforation of the wall of the gallbladder. A sequele of acute cholecystitis. Arch Surg 1942; 44: 677-86.

16. Roslyn JJ, Thompson JE, Darvin H, Den Besten L. Risk factors for gallbladder perforation. Am J Gastroenterol 1987; 82: 636-40.
17. Sood BP, Kalra N, Gupta S, et al. Role of sonography in the diagnosis of gallbladder perforation. J Clin Ultrasound 2002; 30: 270-4.

18. Lennon F, Green WE. Perforation of the gallbladder. A review of 32 cases. J R Coll Surg Edinb 1983; 28: 169-73.

19. Gupta H, Gupta PK, Schuller D, et al. Development and validation of a risk calculator for predicting postoperative pneumonia. Mayo Clin Proc 2013; 88: 1241-9.

20. Johnson RG, Arozullah AM, Neumayer L, et al. Multivariable predictors of post-operative respiratory failure after general and vascular surgery: results from the patient safety in surgery study. J Am Coll Surg 2007; 204: 1188-98.

21. Soltes M, Radoňak J. A risk score to predict the difficulty of elective laparoscopic cholecystectomy. Videosurgery Miniinv 2014; 9: 608-12.

Received: 23.09.2017, accepted: 17.11.2017. 